\title{
Health Benefit Assessment of China's National Action Plan on Air Pollution in the Beijing-Tianjin-Hebei Area
}

\author{
Wenkai Bi, Kui Chen", Zhimei Xiao", Miao Tang, Naiyuan Zheng, Ning Yang, Jingyun Gao, \\ Yuan Li, Jun Kong, Hong Xu
}

Tianjin Eco-Environmental Monitoring Center, Tianjin 300191, China

\begin{abstract}
To evaluate the effect of China's National Action Plan on Air Pollution (NAPAP), we assessed the health benefits of $\mathrm{PM}_{2.5}$ remediation under the NAPAP from 2013 to 2017 in the Beijing-Tianjin-Hebei (BTH) area using a relative risk model with real $\mathrm{PM}_{2.5}$ monitoring data and recent statistical research data. The results revealed that the $\mathrm{PM}_{2.5}$ concentration in the BTH area decreased by $36 \mu \mathrm{g} \mathrm{m}^{-3}(34.0 \%)$ under the NAPAP. $\mathrm{PM}_{2.5}$-related mortality resulting from all causes, cardiovascular disease, respiratory disease and lung cancer decreased to $58.1-65.2 \%$ of that in $2013 ; 102,133 \mathrm{PM}_{2.5}-$ related deaths were avoided, indicating a greater efficacy than the U.S. Cross-State Air Pollution Rule. These results demonstrated that the NAPAP is effective and can be used by other countries as a reference in enacting similar statutes.
\end{abstract}

Keywords: Health benefit assessment; $\mathrm{PM}_{2.5}$; National Action Plan on Air Pollution; Beijing-Tianjin-Hebei area.

\section{INTRODUCTION}

The definition of particulate matter with an aerodynamic diameter less than $2.5 \mu \mathrm{m}\left(\mathrm{PM}_{2.5}\right)$ was established in 1997 by the U.S. Environmental Protection Agency to protect public health (Liang et al., 2016). Since China began monitoring the ambient air $\mathrm{PM}_{2.5}$ concentration nationwide in 2013, $\mathrm{PM}_{2.5}$ has rapidly replaced $\mathrm{PM}_{10}$ as the most common chief pollutant (Pui et al., 2014); the 2013 annual mean $\mathrm{PM}_{2.5}$ concentration of the 74 cities required to monitor ambient air $\mathrm{PM}_{2.5}$ concentration in Phase One (Phase Two for other cities began in 2016) was $72 \mu \mathrm{g} \mathrm{m}^{-3}$ (ranging from $26-160 \mu \mathrm{g} \mathrm{m}^{-3}$ ), and $95.9 \%$ of the cities failed to meet the secondary annual mean standard $\left(35 \mu \mathrm{g} \mathrm{m}^{-3}\right)$ for ambient air quality in China (Ministry of Ecology and Environment of the People's Republic of China, 2012). $\mathrm{PM}_{2.5}$ pollution was especially serious in the Beijing-Tianjin-Hebei (BTH) area (Zhang et al., 2017; Cai et al., 2018), where none of the 13 cities met the standard and 7 were listed among the 10 cities with the worst ambient air quality (Ministry of Ecology and Environment of the People's Republic of China, 2014).

To improve the ambient air quality, as characterized by $\mathrm{PM}_{2.5}$, the Chinese government enacted a statute called the National Action Plan on Air Pollution (NAPAP, 2013-

\footnotetext{
* Corresponding authors.

Tel.: +86-022-87671683; Fax: +86-022-87671692

E-mail address: kuichen@126.com (K. Chen);

xiaozhimei01@163.com (Z.Xiao)
}

2017), which required that the $\mathrm{PM}_{2.5}$ concentration in the BTH area be reduced by $25.0 \%$ by 2017 compared with that in 2013. Furthermore, Beijing was asked to reduce the $\mathrm{PM}_{2.5}$ concentration to approximately $60 \mu \mathrm{g} \mathrm{m}^{-3}$ (The State Council of the People's Republic of China, 2013). Many studies assessed the NAPAP by forecasting the health benefits of $\mathrm{PM}_{2.5}$ remediation attributed to the NAPAP (Lei et al., 2015; Fang et al., 2016; Chen et al., 2017b; Maji et al., 2018). However, most studies selected the $\mathrm{PM}_{2.5}$ concentration target of the NAPAP and utilized outdated population or mortality data as the experimental data. Therefore, the real effect of the NAPAP is still not clear.

The aim of this study is to evaluate the effect of the NAPAP by assessing the health benefits of $\mathrm{PM}_{2.5}$ remediation resulting from the NAPAP in the BTH area between 2013 and 2017. The work is based on a relative risk model using real monitoring data and recent statistical research data. We hope the results will be useful for ambient air quality improvement and health risk control.

\section{MATERIALS AND METHODS}

\section{Study Area}

The BTH area $\left(36^{\circ} 05^{\prime} \mathrm{N}-42^{\circ} 40^{\prime} \mathrm{N}, 113^{\circ} 27^{\prime} \mathrm{E}-119^{\circ} 50^{\prime} \mathrm{E}\right)$ is the largest urban agglomeration in northern China and includes Beijing Municipality, Tianjin Municipality and 11 prefecture-level cities of Hebei Province. In 2016, the area accounted for only $2.2 \%$ of the land area but $8.1 \%$ of the population and $10.2 \%$ of the GDP of China (National Bureau of Statistics of the People's Republic of China, 2017). The important position, dense population and poor ambient air 
quality caused $\mathrm{PM}_{2.5}$-related health problems to be very severe in the BTH area (Zheng et al., 2014; Song et al., 2016, 2017).

\section{Health Risk Model}

Because the exposure-response relationship between the level of exposure to $\mathrm{PM}_{2.5}$ and the mortality was linear or near linear (Krewski et al., 2000; Pope III, 2000; National Research Council (U.S.) Committee on Estimating the Health-Risk-Reduction Benefits of Proposed Air Pollution Regulations, 2002), we selected a widely used epidemiological relative risk model (Broome et al., 2015; Gao et al., 2016; Chen et al., 2017a) to quantify the association between long-term exposure to ambient air $\mathrm{PM}_{2.5}$ and the risk of $\mathrm{PM}_{2.5}$-related disease. The model is as follows:

$$
\begin{gathered}
R R=\exp \left[\beta \cdot\left(C-C_{0}\right)\right] \\
I=\left(\frac{R R-1}{R R}\right) \cdot E \cdot P
\end{gathered}
$$

In Eq. (1), $C_{0}$ represents the critical $\mathrm{PM}_{2.5}$ concentration, below which the health impact of $\mathrm{PM}_{2.5}$ is considered to be approximately $0 . \quad C$ represents the exposed $\mathrm{PM}_{2.5}$ concentration. $\beta$ is the exposure-response coefficient, indicating changes in health effects. $R R$ represents the relative risk.

In Eq. (2), $P$ represents the exposed population. $E$ represents the mortality of disease under $\mathrm{PM}_{2.5}$ concentration C. I represents the $\mathrm{PM}_{2.5}$-related deaths, which we used to assess the health benefits of $\mathrm{PM}_{2.5}$ remediation resulting from the NAPAP.

The mortalities in this study are from all causes, cardiovascular disease, respiratory disease and lung cancer, as the diameter of $\mathrm{PM}_{2.5}$ is small enough to penetrate the bronchioles and alveoli, affecting respiratory function (Turner et al., 2011). Therefore, long-term exposure to $\mathrm{PM}_{2.5}$ mainly contributes to the risk of developing cardiovascular disease, respiratory disease and lung cancer (Englert, 2004; Franklin et al., 2007; Kim et al., 2015).

\section{Scenario Settings and Data Sources}

In this study, we denoted two scenarios - the baseline and the NAPAP - in the BTH area. The baseline scenario represented the health risk in 2013, whereas the NAPAP scenario represented the health risk under the NAPAP in 2017. The difference in $I$ between the two scenarios was used to assess the health benefits from the NAPAP.

The values of $\beta$ used in this study, given in Table 1, were obtained by meta-analysis. To obtain appropriate values, studies used in the meta-analysis were based on the following criteria: (1) focusing on the long-term association of ambient $\mathrm{PM}_{2.5}$ with mortality; (2) including at least one of all-cause mortality, cardiovascular disease mortality, respiratory disease mortality and lung cancer mortality; (3) providing effect estimates such as $\beta$ with standard error or $R R$ with $95 \%$ confidence interval; and (4) studies about
Table 1. Values of the exposure-response coefficients $(\beta)$.

\begin{tabular}{ll}
\hline Causes of death & $\beta\left(\% / 10 \mu \mathrm{g} \mathrm{m}^{-3}\right)$ \\
\hline All causes & 4.30 \\
Cardiovascular disease & 4.97 \\
Respiratory disease & 6.69 \\
Lung cancer & 4.66 \\
\hline
\end{tabular}

China or those conducted in the past 3 years were given priority.

The values of $E$ and $P$ were mainly obtained from statistical yearbooks, reports and relative studies of each city. For the 2017 data that remain unpublished, we estimated the values of $E$ and $P$ from existing data.

$C_{0}$ is defined as the lowest $\mathrm{PM}_{2.5}$ concentration monitored during the exposure time or a threshold recommended by authoritative standards or studies (Apte et al., 2015; Fang et al., 2016). The $C_{0}$ of each city in this study is the air quality guideline $\left(10 \mu \mathrm{g} \mathrm{m}^{-3}\right)$ of the WHO (2006), which is a worldwide guideline and close to the primary annual mean standard $\left(15 \mu \mathrm{g} \mathrm{m}^{-3}\right)$ for ambient air quality in China (Ministry of Ecology and Environment of the People's Republic of China, 2012).

The $C$ under the baseline scenario is 2013 annual mean $\mathrm{PM}_{2.5}$ concentration of each city. The $C$ under the NAPAP scenario is the $\mathrm{PM}_{2.5}$ concentration of each city under the NAPAP. The annual mean $\mathrm{PM}_{2.5}$ concentration was obtained from the environmental status bulletin of each city.

To assess the health benefits from the NAPAP alone, we excluded the effects of meteorological variations and estimated the $\mathrm{PM}_{2.5}$ concentration under the NAPAP. For the three key cities (Beijing, Tianjin and Shijiazhuang) in the BTH area, the average relative humidity decreased, and the average wind speed overall increased between 2013 and 2017. Lower average relative humidity results in a weaker secondary formation of $\mathrm{PM}_{2.5}$, and higher average wind speed is conducive to the spread of pollutants; thus, the diffusion conditions of the BTH area were considered to be better in 2017 on the whole. In fact, according to official statements (Ministry of Ecology and Environment of the People's Republic of China, 2018), the meteorological conditions for pollutant diffusion in the BTH area in 2017 were slightly better than those in 2013; the meteorological variations contributed approximately $5.0 \%$ to the $\mathrm{PM}_{2.5}$ concentration reduction ratio $(39.6 \%)$, and the NAPAP contributed the remaining $34.6 \%$, accounting for approximately $87.4 \%(34.6 \% / 39.6 \%)$ of the reduction in $\mathrm{PM}_{2.5}$ concentration. Thus, the $\mathrm{PM}_{2.5}$ concentration under the NAPAP could be calculated based on the 2017 annual mean $\mathrm{PM}_{2.5}$ concentration, the $\mathrm{PM}_{2.5}$ concentration variation from 2013 to 2017 and the NAPAP contribution.

The details and sources of the above parameters are listed in the Supplementary Material.

\section{RESULTS AND DISCUSSION}

\section{PM $_{2.5}$ Concentration}

We found that under the NAPAP scenario, the $\mathrm{PM}_{2.5}$ concentration of each city in the BTH area improved 
significantly compared with that under the baseline scenario, suggesting that the NAPAP achieved its target. Fig. 1 shows the $\mathrm{PM}_{2.5}$ concentration of each city under the two scenarios. The $\mathrm{PM}_{2.5}$ concentration in the BTH area under the NAPAP scenario was $70 \mu \mathrm{g} \mathrm{m}^{-3}$ (ranging from $\left.32-95 \mu \mathrm{g} \mathrm{m}^{-3}\right)$, which is $36 \mu \mathrm{g} \mathrm{m}^{-3}(34.0 \%)$ lower than that under the baseline scenario (ranging from $40-160 \mu \mathrm{g} \mathrm{m}^{-3}$ ), thus achieving the target of a $25.0 \%$ decrease in $\mathrm{PM}_{2.5}$ concentration. The decrease in each city ranged from 20.0 $43.8 \%$. Every city except Zhangjiakou and Chengde outperformed the $25.0 \%$ target, and Xingtai decreased the most. The low decreases observed in Zhangjiakou and Chengde may be attributed to their already low $\mathrm{PM}_{2.5}$ concentrations in the BTH area, which were 40 and $49 \mathrm{\mu g} \mathrm{m}^{-3}$, respectively, under the baseline scenario. Beijing's $\mathrm{PM}_{2.5}$ concentration under the NAPAP scenario was $62 \mu \mathrm{g} \mathrm{m}^{-3}$, and this city also achieved its goal.

\section{PM $_{2.5}$-Related Mortality}

The $\mathrm{PM}_{2.5}$-related mortality and $\mathrm{PM}_{2.5}$-related mortality ratio (the contribution of the $\mathrm{PM}_{2.5}$-related mortality to the overall mortality) in the BTH area under the NAPAP scenario also notably decreased from that under the baseline scenario.

Fig. 2 shows the $\mathrm{PM}_{2.5}$-related mortality and the ratio from different causes of deaths in the BTH area under the two scenarios. The $\mathrm{PM}_{2.5}$-related all-cause mortality was $1.32 \%$ under the NAPAP scenario, accounting for $58.1 \%$ of that under the baseline scenario. The $\mathrm{PM}_{2.5}$-related mortality of three specific diseases, viz., cardiovascular disease, respiratory disease and lung cancer, was $0.83,0.15$ and $0.11 \%$ respectively, under the NAPAP scenario, accounting for $60.6-65.2 \%$ of that under the baseline scenario.

The ratio of $\mathrm{PM}_{2.5}$-related all-cause mortality was $23.6 \%$ under the NAPAP scenario, 11.0 percentage points lower than that under the baseline scenario. The $\mathrm{PM}_{2.5}$-related mortality ratios of cardiovascular disease, respiratory disease and lung cancer were 26.7, 33.4 and $25.0 \%$ under the NAPAP scenario, which were 12.1, 13.9 and 11.5 percentage points lower, respectively, than those under the baseline scenario.

\section{Health Benefits}

We found that the NAPAP had significant health benefits. Fig. 3 shows the deaths and $\mathrm{PM}_{2.5}$-related deaths in the BTH area under the two scenarios. For the NAPAP scenario, there were 621,488 deaths, 146,941 (23.6\%) of which were related to $\mathrm{PM}_{2.5}$. For the baseline scenario, there were 719,084 deaths, 249,074 (34.6\%) of which were related to $\mathrm{PM}_{2.5}$. Compared with the baseline scenario, $102,133 \mathrm{PM}_{2.5}$-related deaths were avoided in the BTH area due to the NAPAP.

The $\mathrm{PM}_{2.5}$-related deaths of the three specific diseases listed above also decreased under the NAPAP scenario, accounting for $60.2-65.4 \%$ of that under the baseline scenario. For cardiovascular disease, there were 344,611 deaths under the NAPAP scenario, 91,985 (26.7\%) of which were related to $\mathrm{PM}_{2.5}$, which was 58,085 (12.1 percentage points) fewer deaths than that under the baseline scenario. For respiratory disease, there were 49,233 deaths under the NAPAP, 16,448 (33.4\%) of which were related to $\mathrm{PM}_{2.5}$, which was 8,693 (13.9 percentage points) fewer deaths than that under the baseline scenario. For lung cancer, there were 46,829 deaths under the NAPAP scenario, 11,713 (25.0\%) of which were related to $\mathrm{PM}_{2.5}$, which was 7,740 (11.4 percentage points) fewer deaths than that under the baseline scenario.
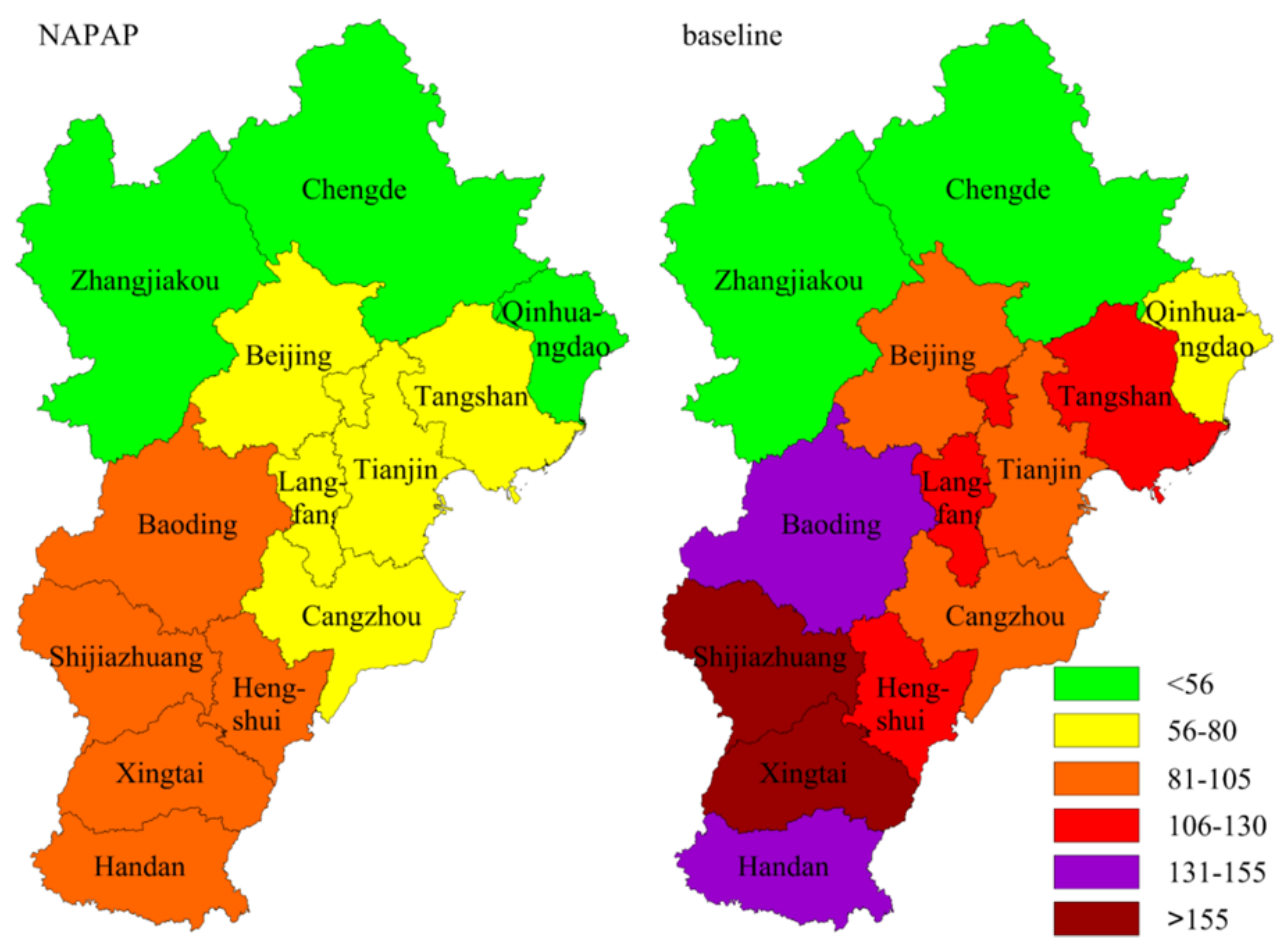

Fig. 1. $\mathrm{PM}_{2.5}$ concentration $\left(\mu \mathrm{g} \mathrm{m}^{-3}\right)$ of each city in the BTH area under the two scenarios. 


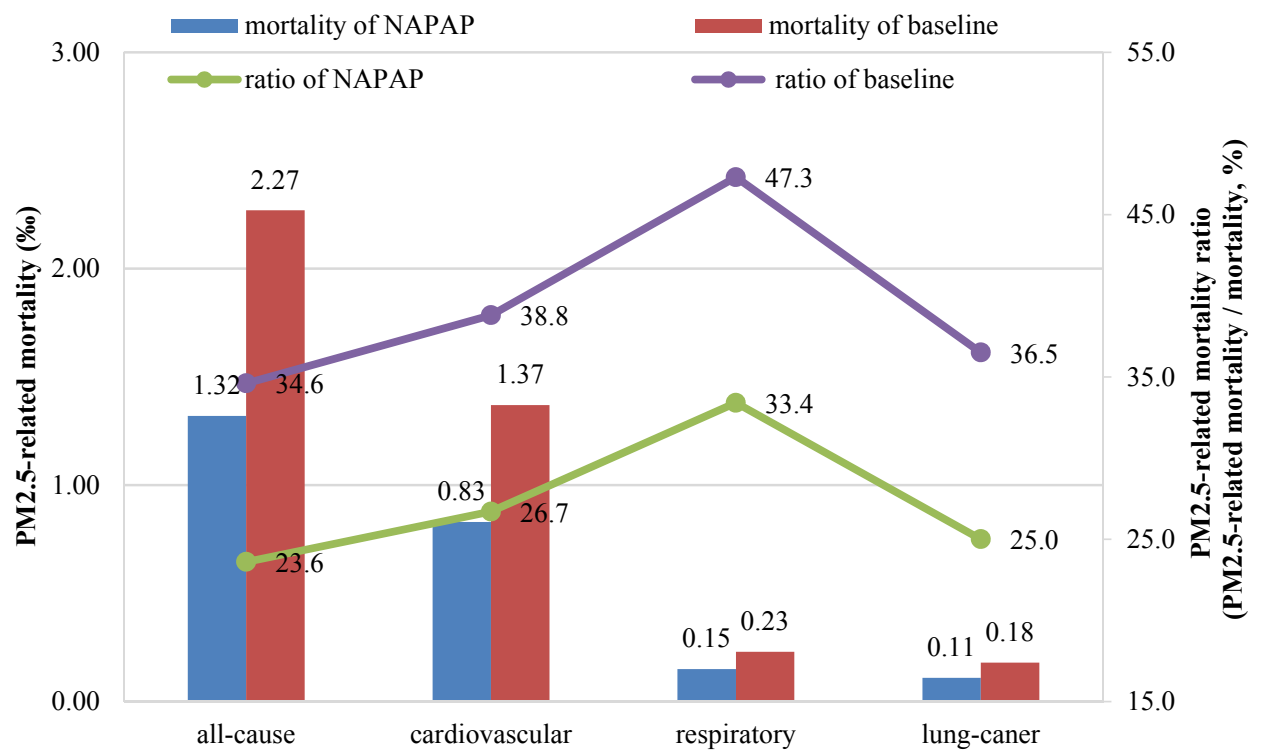

Fig. 2. $\mathrm{PM}_{2.5}$-related mortality and $\mathrm{PM}_{2.5}$-related mortality ratio in the $\mathrm{BTH}$ area under the two scenarios.

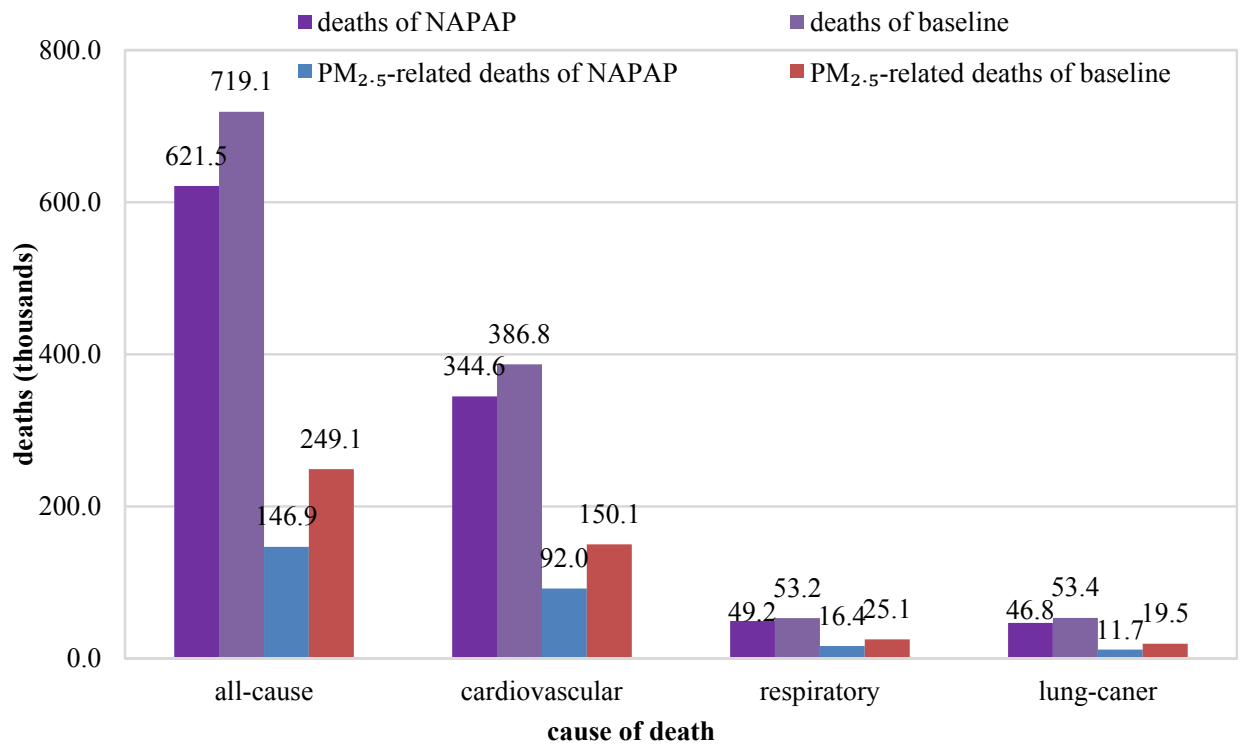

Fig. 3. Deaths and $\mathrm{PM}_{2.5}$-related deaths in the $\mathrm{BTH}$ area under the two scenarios.

Fig. 4 shows the spatial distribution of $\mathrm{PM}_{2.5}$-related deaths in the BTH area under the two scenarios. The average number of $\mathrm{PM}_{2.5}$-related deaths in each city in the BTH area under the NAPAP scenario was 11,303 (ranging from 2,479-21,022), 7,856 fewer than those under the baseline scenario (ranging from 4,171-34.718). Shijiazhuang, Beijing and Tangshan were the top 3 most-improved cities, with an average of 13,413 avoided deaths (ranging from 12,149-14,393), while Qinhuangdao, Chengde and Zhangjiakou were the bottom 3 cities, with an average of 1,596 avoided deaths (ranging from 1,476-1.692).

The NAPAP was shown to be more effective than the U.S. Cross-State Air Pollution Rule. The latter rule led to approximately 23,500 avoided deaths per year (Lei et al., 2015), approximated to 117,500 avoided deaths in 5 years for the whole U.S., which is 15,367 (15.0\%) more than the avoided deaths in the BTH area under the NAPAP scenario. However, considering the U.S. population was approximately 3 times that of the BTH area, the NAPAP was obviously more efficient.

Economic benefits arising from improved health in the BTH area of the NAPAP were also significant and worthwhile. According to related studies (Zeng and Jiang, 2010; Huang and Zhang, 2013), the value of statistical life in health costs attributable to China's air pollution was approximately 1 million CNY per person. Therefore, the economic benefits brought about by improved health alone reached approximately 102.1 billion CNY, which accounted for $41.0 \%$ of the NAPAP direct investment in the BTH area (Chinese Academy for Environmental Planning, 2015). 

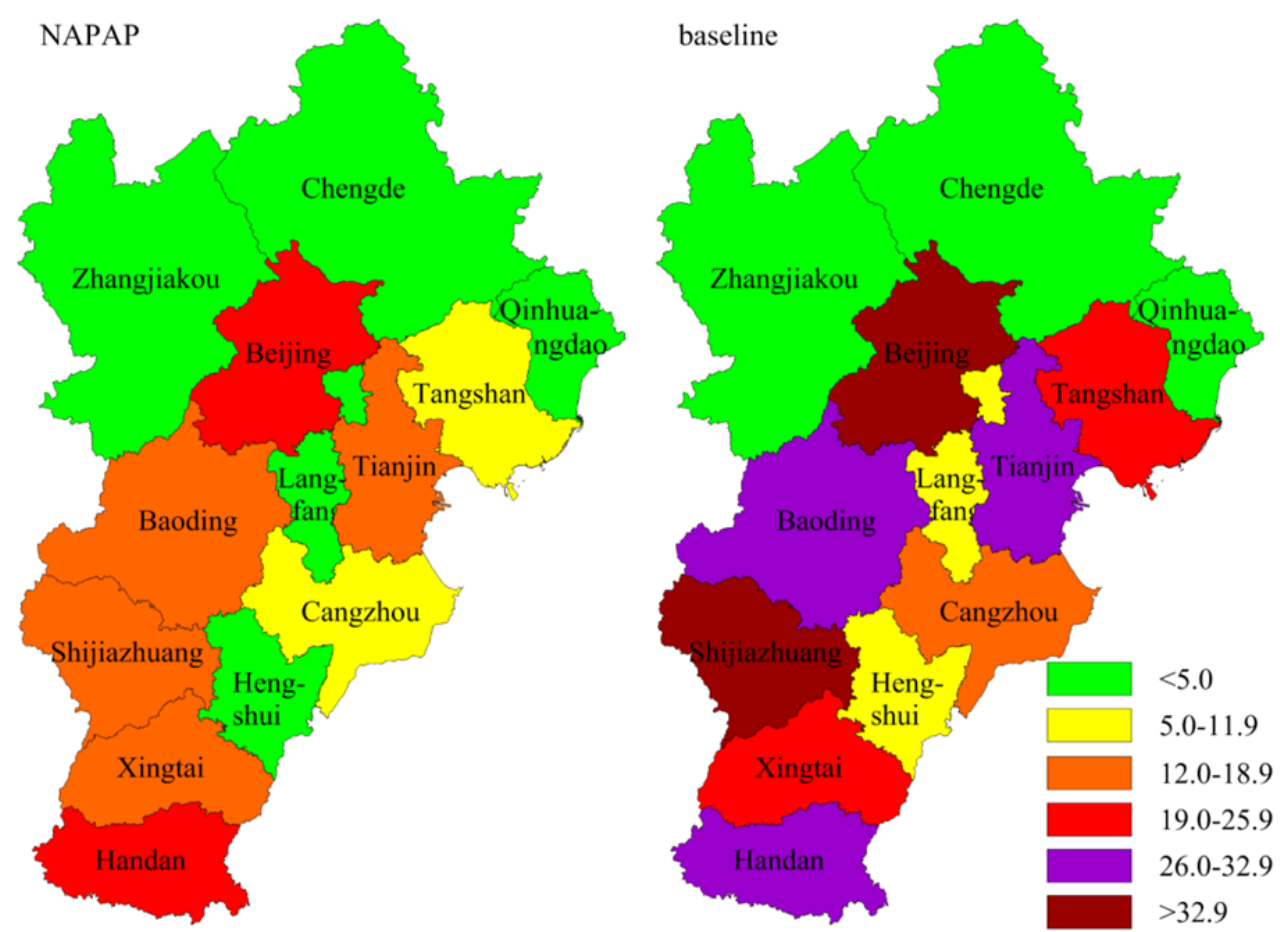

Fig. 4. $\mathrm{PM}_{2.5}$-related deaths (thousands) in the BTH area under the two scenarios.

\section{Comparison with Related Studies}

Previous studies have focused on the same question addressed here. By assuming the exact NAPAP target, Lei et al. (2015) estimated that the avoided deaths in the BTH area should be 89,000 , which was 13,133 (12.9\%) fewer deaths than our results. The difference arose from two reasons. The first reason was the difference in $\beta$. The $\beta$ in the previous study, which took the lower limit of that used in the U.S., was $3.0 \% / 10 \mu \mathrm{g} \mathrm{m}^{-3}$ (ranging from 2.0$\left.4.0 \% / 10 \mu \mathrm{g} \mathrm{m}^{-3}\right), 1.3 \% / 10 \mu \mathrm{g} \mathrm{m}^{-3}$ lower than our value. The second reason was the uncertainty in $\mathrm{PM}_{2.5}$ concentrations. The $\mathrm{PM}_{2.5}$ concentrations in the previous study were from Community Multiscale Air Quality, an air quality forecasting model, which may cause uncertainty in comparison with real monitoring data. Furthermore, the previous study showed a $34.0 \%$ decrease in the $\mathrm{PM}_{2.5}$ concentrations but provided no detailed figures.

Under the same assumptions, Chen et al. (2017b) estimated that the deaths prevented in the BTH area should be 70,255 (14,051 per year over 5 years), which was 31,878 (31.2\%) fewer deaths than in our study. The difference was mainly attributed to the difference in the $\mathrm{PM}_{2.5}$ concentration. The previous study obtained $2012 \mathrm{PM}_{2.5}$ monitoring data from Beijing, Tianjin and Shijiazhuang and selected 2012 as the baseline year. However, the official monitoring and reporting of $\mathrm{PM}_{2.5}$ concentrations in China began in 2013, and to the best of our knowledge, no $\mathrm{PM}_{2.5}$ concentrations were publicly available in 2012 . The 2012 concentration in the previous study was $84 \mu \mathrm{g} \mathrm{m}^{-3}$, which was $22 \mu \mathrm{g} \mathrm{m}^{-3}$ lower than that in our baseline year. Moreover, the concentration in the previous study decreased by approximately $21 \mu \mathrm{g} \mathrm{m}^{-3}$ (25\%) from the baseline year to 2017 , which was $15 \mu \mathrm{g} \mathrm{m}^{-3}$ lower than the actual result.
According to the research results of Yang et al. (2013), the ambient air $\mathrm{PM}_{2.5}$-related mortality ranked fourth in causes of mortality after diet $(30.6 \%$, among all reported deaths), high blood pressure (24.6\%), and tobacco (16.4\%). Our $\mathrm{PM}_{2.5}$-related mortality ratio was $34.6 \%$ under the baseline scenario and $23.6 \%$ under the NAPAP scenario, both of which are much higher than that of tobacco. However, the study period in the previous study was from 1990 to 2010, and the lack of $\mathrm{PM}_{2.5}$ monitoring data and the rapid change in China in the years after may have led to the differences. Nonetheless, the previous study provided a reference; that is, the NAPAP reduced $\mathrm{PM}_{2.5}$-related health risks from a level exceeding the risk factor for diet to a level near that of high blood pressure.

Though our results were robust and realistic, some limitations should be noted. Since certain data were unavailable, some of the populations and mortalities were estimated rather than drawn from public statistics. One key index with which to assess the health benefit - the years of life lost (YLL) - could not be obtained, and the exposureresponse coefficient was taken from a meta-analysis of the latest study data rather than authoritative results. Thus, we suggest that further studies should focus on local exposureresponse coefficients and improving assessments by incorporating the YLL.

\section{CONCLUSIONS}

We verified the effect of the NAPAP by assessing the health benefits of $\mathrm{PM}_{2.5}$ remediation in the $\mathrm{BTH}$ area under this plan. To the best of our knowledge, this is the first and the most accurate study assessing the NAPAP in the BTH area using real $\mathrm{PM}_{2.5}$ monitoring data and recent statistical 
research data.

The NAPAP was effective, as the $\mathrm{PM}_{2.5}$ concentration in the BTH area decreased by $36 \mu \mathrm{g} \mathrm{m}^{-3}(34.0 \%)$ from 2013 to 2017, achieving the target set for this area. The $\mathrm{PM}_{2.5^{-}}$ related mortality caused by all causes, cardiovascular disease, respiratory disease and lung cancer in the BTH area under this plan was $1.32,0.83,0.15$ and $0.11 \%$, respectively, accounting for $58.1-65.2 \%$ of the values in the baseline scenario. The $\mathrm{PM}_{2.5}$-related mortality ratio was $23.6 \%$, 11.0 percentage points lower than in the baseline scenario.

Under the NAPAP, 102,133 deaths were avoided in the BTH area, and CNY 102.1 billion were saved. The NAPAP was more efficient in improving health than the U.S. Cross-State Air Pollution Rule. Although the $\mathrm{PM}_{2.5^{-}}$ related mortality in the $\mathrm{BTH}$ area decreased from a value exceeding diet-related mortality to the same mortality risk as that of high blood pressure, it was still high.

This study confirmed the benefits of the NAPAP, proving that the ambient air quality can be improved through effective state planning. We believe that the NAPAP provides a reference for other countries in improving their ambient air quality and, furthermore, promotes the improvement of ambient air quality worldwide.

\section{ACKNOWLEDGMENTS}

This research was financially supported by the Projects for Science and Technology of Tianjin (16YFZCSF00260) and the National Key R\&D Program of China (2016YFC0208501, 2016YFC0208502, and 2016YFC0208506).

\section{SUPPLEMENTARY MATERIAL}

Supplementary data associated with this article can be found in the online version at http://www.aaqr.org.

\section{REFERENCES}

Apte, J.S., Marshall, J.D., Cohen, A.J. and Brauer, M. (2015). Addressing global mortality from ambient $\mathrm{PM}_{2.5}$. Environ. Sci. Technol. 49: 8057-8066.

Broome, R.A., Fann, N., Cristina, T.J., Fulcher, C., Duc, H. and Morgan, G.G. (2015). The health benefits of reducing air pollution in Sydney, Australia. Environ. Res. 143: 19-25.

Cai, K., Li, S.S., Zheng, F.B., Yu, C., Zhang, X.Y., Liu, Y. and $\mathrm{Li}, \mathrm{Y}$. (2018). Spatio-temporal variations in $\mathrm{NO}_{2}$ and $\mathrm{PM}_{2.5}$ over the central plains economic region of China during 2005-2015 based on satellite observations. Aerosol Air Qual. Res. 18: 1221-1235.

Chen, L., Shi, M., Li, S., Bai, Z. and Wang, Z. (2017a). Combined use of land use regression and BenMAP for estimating public health benefits of reducing $\mathrm{PM}_{2.5}$ in Tianjin, China. Atmos. Environ. 152: 16-23.

Chen, L., Shi, M., Li, S., Gao, S., Zhang, H., Sun, Y., Mao, J., Bai, Z., Wang, Z. and Zhou, J. (2017b). Quantifying public health benefits of environmental strategy of $\mathrm{PM}_{2.5}$ air quality management in Beijing-Tianjin-Hebei region.
Chin. J. Environ. Sci. 57: 33-40.

Chinese Academy for Environmental Planning (2015). Investment and financing needs and impacts of the national action plan on air pollution (2013-2017). http://www.cleanairchina.org/file/loadFile/110.html, Last Access: 19 November 2015.

Englert, N. (2004). Fine particles and human health-A review of epidemiological studies. Toxicol. Lett. 149: 235-242.

Fang, D., Wang, Q.G., Li, H., Yu, Y., Lu, Y. and Qian, X. (2016). Mortality effects assessment of ambient $\mathrm{PM}_{2.5}$ pollution in the 74 leading cities of China. Sci. Total Environ. 569-570: 1545-1552.

Franklin, M., Zeka, A. and Schwartz, J. (2007). Association between $\mathrm{PM}_{2.5}$ and all-cause and specificcause mortality in 27 US communities. J. Exposure Sci. Environ. Epidemiol. 17: 279-287.

Gao, J., Yuan, Z., Liu, X., Xia, X., Huang, X. and Dong, Z. (2016). Improving air pollution control policy in China-A perspective based on cost-benefit analysis. Sci. Total Environ. 543: 307-314.

Huang, D.S. and Zhang, S.Q. (2013). Health benefit evaluation for $\mathrm{PM}_{2.5}$ Pollution control in BeijingTianjin-Hebei region of China. China Environ. Sci. 33: 166-174.

Kim, K.H., Kabir, E. and Kabir, S. (2015). A review on the human health impact of airborne particulate matter. Environ. Int. 74: 136-143.

Krewski, D., Burnett, R.T., Goldberg, M.S., Hoover, K., Siemiatycki, J., Jerrett, M., Abrahamowicz, M. and White, W.H. (2000). Reanalysis of the harvard six cities study and the American cancer society study of particulate air pollution and mortality, A special report of the institute's particle epidemiology reanalysis project. Final Version. https://www.healtheffects.org/system/files/ HEI-Reanalysis-2000.pdf, Last Access: 26 October 2018.

Lei, Y., Xue, W., Zhang, Y. and Xu, Y. (2015). Health benefit evaluation for air pollution prevention and control action plan in China. Chin. J. Environ. Manage. 5: 50-53.

Liang, C.S., Duan, F.K., He, K.B. and Ma, Y.L. (2016). Review on recent progress in observations, source identifications and countermeasures of $\mathrm{PM}_{2.5}$. Environ. Int. 86: 150-170.

Maji, K.J., Dikshit, A.K., Arora, M. and Deshpande, A. (2018). Estimating premature mortality attributable to $\mathrm{PM}_{2.5}$ exposure and benefit of air pollution control policies in China for 2020. Sci. Total Environ. 612: 683-693.

Ministry of Ecology and Environment of the People's Republic of China (2012). Ambient air quality standards, http://kjs.mep.gov.cn/hjbhbz/bzwb/dqhjbh/dqhjzlbz/201 203/W020120410330232398521.pdf, Last Access: 29 February 2012

Ministry of Ecology and Environment of the People's Republic of China (2014). China environment condition bulletin 2013, http://www.mep.gov.cn/hjzl/zghjzkgb/ln zghjzkgb/201605/P020160526564151497131.pdf, Last Access: 27 May 2014. 
Ministry of Ecology and Environment of the People's Republic of China (2018). The regular press conference record of Ministry of Ecology and Environment of The People's Republic of China in February 2018, http://www.mep.gov.cn/gkml/sthjbgw/qt/201802/t20180 227 431875.htm, Last Access: 08 March 2018.

National Bureau of Statistics of the People's Republic of China (2017). China statistical yearbook, China Statistics Press, Beijing.

National Research Council (U.S.) Committee on Estimating the Health-Risk-Reduction Benefits of Proposed Air Pollution Regulations. (2002). Estimating the public health benefits of proposed air pollution regulations. The National Academies Press, Washington, D.C., USA. Pope III, C.A. (2000). Epidemiology of fine particulate air pollution and human health: Biologic mechanisms and who's at risk? Environ. Health Perspect. 108: 713-723.

Pui, D.Y.H., Chen, S.C. and Zuo, Z. (2014). $\mathrm{PM}_{2.5}$ in China: Measurements, sources, visibility and health effects, and mitigation. Particuology 13: 1-26.

Song, C., He, J., Wu, L., Jin, T., Chen, X., Li, R., Ren, P., Zhang, L. and Mao, H. (2017). Health burden attributable to ambient $\mathrm{PM}_{2.5}$ in China. Environ. Pollut. 223: 575586.

Song, Y., Wang, X., Maher, B.A., Li, F., Xu, C., Liu, X., Sun, X. and Zhang, Z. (2016). The spatial-temporal characteristics and health impacts of ambient fine particulate matter in China. J. Clean. Prod. 112: 13121318.

The State Council of the People's Republic of China (2013). National action plan on air pollution, http://ww w.gov.cn/zwgk/2013-09/12/content_2486773.htm, Last
Access: 10 September 2013.

Turner, M.C., Krewski, D., Pope III, C.A., Chen, Y., Gapstur, S.M. and Thun, M.J. (2011). Long-term ambient fine particulate matter air pollution and lung cancer in a large cohort of never-smokers. Am. J. Respir. Crit. Care. Med. 184: 1374-1381.

World Health Organization (2006). WHO air quality guidelines for particulate matter, ozone, nitrogen dioxide and sulfur dioxide, WHO Press, Geneva.

Yang, G., Wang, Y., Zeng, Y., Gao, G.F., Liang, X., Zhou, M., Wan, X., Yu, S., Jiang, Y., Naghavi, M., Vos, T., Wang, H., Lopez, A.D. and Murray, C.J. (2013). Rapid health transition in China, 1990-2010: Findings from the Global Burden of Disease Study 2010. Lancet 381: 1987-2015.

Zeng, X.G. and Jiang, Y. (2010). Evaluation of value of statistical life in health costs attributable to air pollution. China Environ. Sci. 30: 284-288.

Zhang, Y.L., Zhu, B., Gao, J.H., Kang, H.Q., Yang, P., Wang, L.L. and Zhang, J.K. (2017). The source apportionment of primary $\mathrm{PM}_{2.5}$ in an aerosol pollution event over Beijing-Tianjin-Hebei region using WRF-Chem, China. Aerosol Air Qual. Res. 17: 2966-2980.

Zheng, S., Pozzer, A., Cao, C.X. and Lelieveld, J. (2014). Long-term (2001-2012) fine particulate matter $\left(\mathrm{PM}_{2.5}\right)$ and the impact on human health in Beijing, China. Atmos. Chem. Phys. 14: 5715-5725.

Received for review, September 5, 2018 Revised, November 9, 2018 Accepted, November 20, 2018 